\title{
Translation of an Efficacious Cancer- Screening Intervention to Women Enrolled in a Medicaid Managed Care Organization
}

\author{
Allen J. Dietrich, $M D^{1,2}$ \\ Jonathan N. Tobin, $P b D^{3,4}$ \\ Andrea Cassells, $\mathrm{MPH}^{3}$ \\ Cbristina M. Robinson, MS ${ }^{2}$ \\ Meredith Reb, MPA \\ Karen A. Romero, MPA ${ }^{5}$ \\ Ann Barry Flood, $P b D^{2,6}$ \\ Michael L. Beach, MD, PbD ${ }^{1,7}$ \\ ${ }^{1}$ Norris Cotton Cancer Center, Dartmouth \\ Medical School, Lebanon, NH \\ ${ }^{2}$ Department of Community and Family \\ Medicine, Dartmouth Medical School, \\ Lebanon, $\mathrm{NH}$ \\ ${ }^{3}$ Clinical Directors Network, New York, NY \\ ${ }^{4}$ Department of Epidemiology and Popula- \\ tion Health, Albert Einstein College of \\ Medicine of Yeshiva University, Bronx, NY \\ ${ }^{5}$ Affinity Health Plan, Bronx, NY \\ ${ }^{6}$ Department of Sociology, Dartmouth \\ College, Lebanon, $\mathrm{NH}$ \\ ${ }^{7}$ Department of Anesthesiology, Dartmouth \\ Medical School, Lebanon, NH
}

Conflicts of interest: none reported

\section{CORRESPONDING AUTHOR}

Allen J. Dietrich, MD

Department of Community

and Family Medicine

7927 Rubin, Room 834

Dartmouth Hitchcock Medical Center

1 Medical Center Dr

Lebanon, NH 03766

Allen.J.Dietrich@dartmouth.edu

\begin{abstract}
PURPOSE An earlier randomized controlled trial of prevention care management (PCM) found significant improvement in breast, cervical, and colorectal cancerscreening rates among women attending Community Health Centers but required substantial research support. This study evaluated the impact of a streamlined PCM delivered through a Medicaid managed care organization (MMCO), an infrastructure with the potential to sustain this program for the long term.
\end{abstract}

METHODS This randomized trial was conducted within an MMCO serving New York City between May 2005 and December 2005. A total of 1,316 women aged 40 to 69 years and not up to date for at least 1 targeted cancer-screening test were randomized to either PCM or a comparison group. Women in the PCM group received up to 3 scripted telephone calls to identify barriers and provide support to obtain any needed breast, cervical, and colorectal cancer-screening tests. Women in the comparison group received a modified version of the MMCO's established mammography telephone outreach program, also in up to 3 calls. Women in both groups received a financial incentive on confirmation that they had received a mammogram. Screening status was assessed through MMCO administrative data. Groups were compared using odds ratios.

RESULTS In an intent-to-treat comparison adjusted for baseline screening status, PCM women were 1.69 times more likely to be up-to-date for colorectal cancerscreening tests at follow-up than women in the comparison group (95\% confidence interval, 1.03-2.77). Follow-up screening rates for cervical and breast cancer did not differ significantly between study groups on an intent-to-treat basis.

CONCLUSIONS The abbreviated PCM telephone intervention was feasible to deliver through an $\mathrm{MMCO}$ and improved screening for 1 cancer. This approach has the potential to improve cancer-screening rates significantly in settings that can provide telephone support to women known to be overdue.

Ann Fam Med 2007;5:320-327. DOI: 10.1370/afm.701.

\section{INTRODUCTION}

【 ower cancer-screening rates among low-income and minority women may contribute to more late-stage diagnoses and higher rates of cancer mortality. ${ }^{1-6}$ Although socioeconomic variables such as income and education may explain much of the disparity in cancer screening observed between racial and ethnic groups, ${ }_{1}^{2,7,8}$ disparities nonetheless remain. Recent surveys in New York City found that Hispanics and African Americans were less likely to be screened for colorectal cancer than whites, ${ }^{9,10}$ and cancer mortality rates were 1.3 times higher among residents living in low-income areas than among their counterparts in higher-income areas. ${ }^{11}$

A previously reported randomized controlled trial of a prevention care management (PCM) intervention found an improvement in cancer- 
screening status with the intervention among women receiving health care from participating federally funded Community Health Centers. ${ }^{12}$ PCM is a telephone-based intervention delivered by trained staff to women who were not up-to-date for breast, cervical, or colorectal cancer screening, to help them overcome barriers to receiving needed tests. The intervention significantly increased screening rates for all 3 types of cancer $^{12}$ among this primarily low-income and minority population. ${ }^{13}$ The earlier trial, however, required labor-intensive reviews of patient medical records and used research staff to recruit women from Community Health Center waiting rooms and to provide care management support. Through a National Cancer Institute dissemination supplement, we conducted a practical clinical trial ${ }^{14,15}$ to evaluate the impact of a less resource-intensive modification of PCM implemented through a potentially sustainable resource-the quality improvement infrastructure of a Medicaid managed care organization (MMCO).

MMCOs have several strengths for translational work of this type. Their billing and administrative databases contain cancer-screening information that can efficiently identify patients needing services and evaluate whether services are subsequently obtained. Claims-based screening data can be more accurate than both medical records ${ }^{16,17}$ and patient self-report. ${ }^{18}$ In addition, many MMCOs use sophisticated customer relations management software and have experienced staff who can provide telephone outreach to members, an essential component of the PCM intervention.

Interventions have increased cancer-screening rates in Community Health Centers over the short term, ${ }_{1}{ }^{1}$ but these improved rates diminished substantially with time after the end of research support. ${ }^{20}$ Health care professionals and Community Health Center staff alike face an intimidating array of competing demands in their delivery of patient care, ${ }^{21}$ demands that can take on more urgency than preventive care. An intervention that could be integrated within an MMCO's existing outreach activities could lead to sustainable improvements in cancer-screening rates. To that end, we conducted a study of the PCM intervention modified to be compatible with the existing clinical outreach program of one $\mathrm{MMCO}$ and used administrative data to evaluate the impact on breast, cervical, and colorectal cancer-screening rates among enrolled women.

\section{METHODS}

\section{Settings}

Dartmouth Medical School, Affinity Health Plan (the $\mathrm{MMCO}$ ), and Clinical Directors Network ${ }^{22}$ collabo- rated on this project. Affinity was founded in 1986 as an independent, not-for-profit managed care company dedicated to serving the needs of low- and moderate-income populations in and around New York City. Clinical Directors Network, a practice-based research network in New York City, served as the intermediary organization during this dissemination project, recruiting Affinity Health Plan and participating Community Health Centers, and training Affinity staff. Six Community Health Centers with a sufficient number of potentially eligible Affinity enrollees and previous research experience were selected to participate.

The project was reviewed by Dartmouth's Committee for the Protection of Human Subjects, the institutional review boards of both Montefiore Medical Center and Clinical Directors Network, Albert Einstein College of Medicine's Committee on Clinical Investigations, and Affinity's Research Board. Because all patient contact took place within the framework of Affinity's Quality Improvement programs, and Dartmouth and Clinical Directors Network received only deidentified patient data, the respective institutional review boards did not require informed consent.

\section{Participants}

Eligible women, identified through Affinity's administrative database, were aged 40 to 69 years, received care at 1 of 6 participating Community Health Centers, had been enrolled with Affinity for at least 12 months, and were overdue for at least 1 of the targeted cancer-screening tests.

Definitions of up-to-date status were derived from US Preventive Services Task Force guidelines ${ }^{23-25}$ and matched Health Plan Employer Data and Information Set (HEDIS) breast and cervical cancer-screening guidelines used to assess the quality of MMCOs. ${ }^{26}$ Up-to-date screening status for breast cancer required mammography within 2 years; for cervical cancer, a Papanicolaou test within 3 years; and for colorectal cancer (limited to women aged 50 years and older), home fecal occult blood testing within the past year, sigmoidoscopy or double-contrast barium enema within 5 years, or colonoscopy within 10 years. We were not able to distinguish between screening and diagnostic tests in the administrative data.

\section{Design}

Eligible women were stratified by Community Health Center and then by age decade, then randomized to receive the PCM intervention or Affinity's Mammography Outreach Program (AMOP), both of which are described below. Women could decline to participate in either program without compromising their health care or insurance. 


\section{Interventions}

Figure 1 summarizes the similarities and differences between the AMOP and PCM interventions. At the start of this project, Affinity had an ongoing outreach program in place to promote breast cancer screening. In this program, a trained bilingual outreach specialist completed up to 3 telephone calls with women. During the first call, she described the program, encouraged participation, and if the woman agreed, scheduled a mammography appointment. During the second call, the outreach specialist reminded the patient of her upcoming mammography appointment, and during the third call, she verified that the patient had received a mammogram. On confirmation that a mammogram had been received, the patient was given a $\$ 25$ gift certificate.

\section{AMOP Intervention}

During the current study, the comparison group received this established program with 2 modest additions: (1) a mailed brochure providing educational information on breast, cervical, and colorectal cancer screening, and (2) a brief recommendation during the first telephone call to discuss colorectal and cervical cancer screening with their health care professional. We subsequently refer to this comparison group as the AMOP group.

\section{PCM Intervention}

Women assigned to the PCM intervention received Affinity's Clinical Outreach Program with important enhancements. First, the content of the calls was expanded to include a detailed assessment of barriers to cancer screening. Here, women who were not up-todate for any of the 3 screening tests were asked about specific barriers that had prevented them from being screened. These barrier assessments were informed by interviews conducted during the prior PCM trial. ${ }^{27} \mathrm{Sec}-$ ond, scripted support was provided to help overcome any barriers. In addition to patient education, this support could include help scheduling primary care and screening appointments for needed tests, and reminders about upcoming appointments. MMCO outreach staff received 6 hours of training in providing PCM.

Colorectal cancer-screening support was provided only to women aged 50 years and older. As with the AMOP group, all PCM women who completed a mammogram received a $\$ 25$ gift certificate, but no separate financial incentive was provided to women who became up-todate on cervical or colorectal cancer-screening tests.

It should be noted that the PCM intervention as delivered in this study was modified in 3 important ways from that in the original study. ${ }^{12}$ First, telephone

Figure 1. Relationship of the randomized trial study groups to the established program.

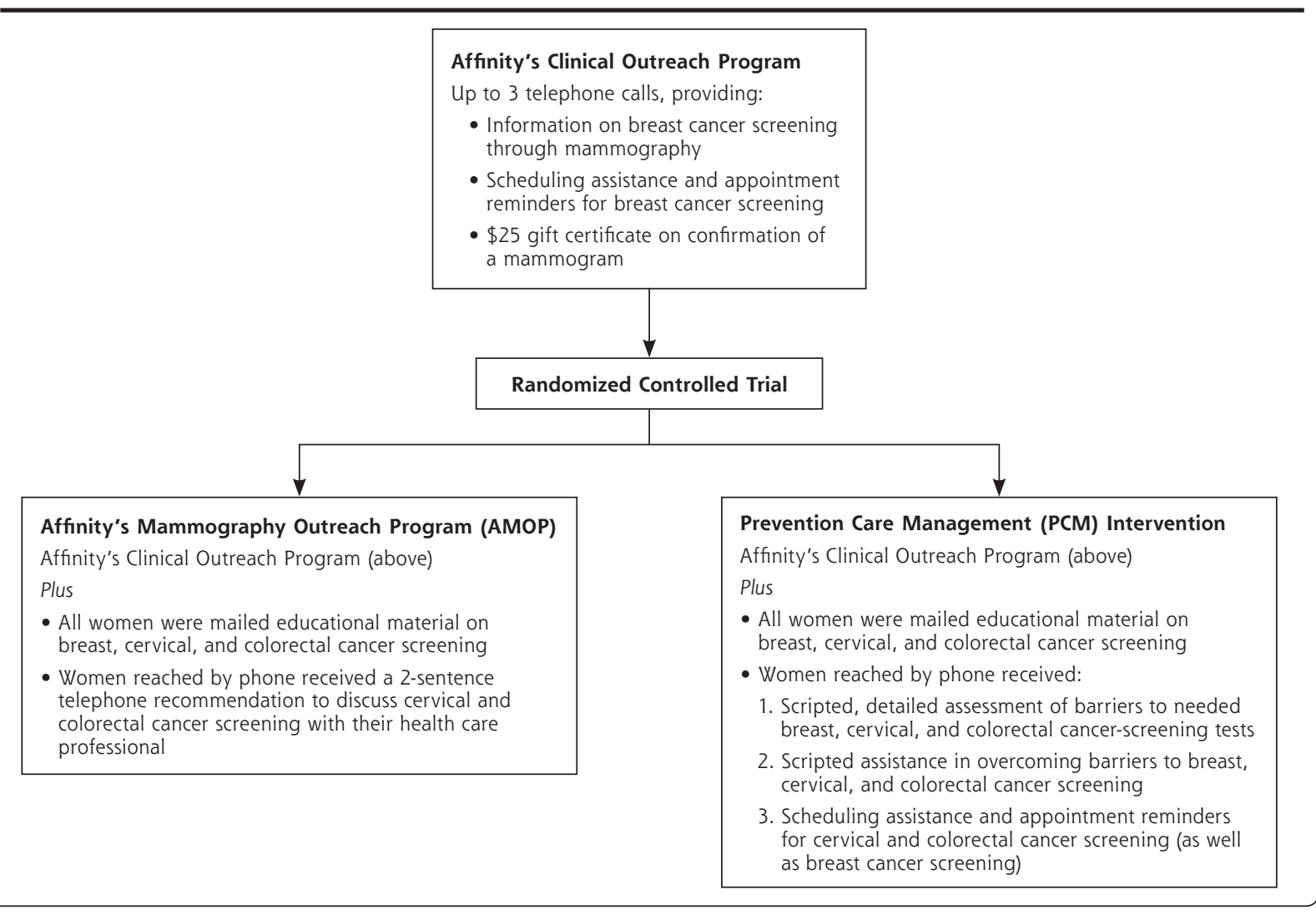


support was provided in no more than 3 calls. In the earlier study, there was no restriction on the number of contacts between care managers and women. Second, calls were provided within a shorter time frame, no more than 8 months, rather than 18 months in the earlier study. Third, initial attempts to contact women were limited to 3 tries, whereas up to 8 tries were made in the earlier project.

\section{Both Interventions}

In both groups, Spanish-speaking patients received telephone support and educational materials in Spanish. Three outreach staff made calls to women in this study; 2 called both AMOP and PCM patients, and 1 called only AMOP patients.

\section{Evaluation}

We used administrative data to evaluate the impact of the intervention. Up-to-date status of women was assessed twice using Current Procedural Terminology and other administrative codes indicative of the screening service: on May 1, 2005, for baseline measures and on March 31, 2006, for follow-up, allowing 3 months for data to enter the administrative system after the intervention.

\section{Analysis}

The main intent-to-treat analysis included all randomized women regardless of whether a successful contact was made; the subgroup analysis included only randomized women who were contacted at least once, were still insured by Affinity and receiving care at the par-

\begin{tabular}{|c|c|c|}
\hline Characteristic & $\begin{array}{l}\text { PCM } \\
\text { Mean (SD) or No. (\%) } \\
(n=663)\end{array}$ & $\begin{array}{l}\text { AMOP } \\
\text { Mean (SD) or No. (\%) } \\
(n=653)\end{array}$ \\
\hline \multicolumn{3}{|l|}{ Age, y } \\
\hline Mean & 50.3 (7.14) & $50.0(6.90)$ \\
\hline $40-49$ & $346(52.2)$ & $344(52.7)$ \\
\hline $50-59$ & 242 (36.5) & $240(36.8)$ \\
\hline$\geq 60$ & $75(11.3)$ & 69 (10.6) \\
\hline \multicolumn{3}{|c|}{$\begin{array}{l}\text { Time since initial enrollment } \\
\text { with Affinity, } y^{*}\end{array}$} \\
\hline $1-3$ & $388(58.5)$ & $372(57.0)$ \\
\hline $3-5$ & $48(7.2)$ & $58(8.9)$ \\
\hline$>5$ & $227(34.2)$ & $222(34.0)$ \\
\hline \multicolumn{3}{|l|}{ Primary language ${ }^{\dagger}$} \\
\hline English & $336(85.7)$ & 316 (81.0) \\
\hline Spanish & $52(13.3)$ & 71 (18.2) \\
\hline Other & $4(1.0)$ & $3(0.8)$ \\
\hline \multicolumn{3}{|c|}{$\begin{array}{l}\mathrm{PCM}=\text { prevention care management; AMOP = Affinity Mammography Outreach Program (the compari- } \\
\text { son group). }\end{array}$} \\
\hline \multicolumn{3}{|c|}{$\begin{array}{l}\text { * Women had to have been enrolled with Affinity for at least } 1 \text { year to be eligible for this study. } \\
\text { †Primary language was derived from administrative records; no primary language was noted for } 271 \text { PCM } \\
\text { women and } 263 \text { AMOP women. }\end{array}$} \\
\hline
\end{tabular}

ticipating Community Health Center, and were willing to participate. Affinity provided deidentified data to the Dartmouth statistician, who compared up-to-date rates between groups at baseline and follow-up for the 3 cancer-screening tests using odds ratios. We calculated odds ratios and $95 \%$ confidence intervals (CIs), using a $P$ value of less than or equal to .05 to indicate statistical significance. We used logistic regression models for breast and cervical cancer screening to adjust for age (40 to 49 years, 50 years and older) and baseline screening status. Because colorectal screening analysis was limited to women aged 50 years or older, logistic regression models for this screening were used to adjust only for baseline screening status. STATA (Stata Corp, College Station, Texas) ${ }^{28}$ was used for data analysis.

\section{RESULTS}

Affinity identified 1,316 eligible women at the 6 Community Health Centers. Their mean age was about 50 years; slightly more than one-half of the women were aged 40 to 49 years (Table 1 ). Of the approximately $60 \%$ of women with a primary language documented in administrative data, about $83 \%$ spoke English and $15 \%$ spoke Spanish. Eligibility required women to be enrolled with Affinity for at least 1 year; most had been enrolled for 3 years or less, whereas about one-third had been enrolled for 5 years or more.

Similar proportions of both study groups were successfully contacted and received the intervention to which they had been assigned (Figure 2). Some 40.4\% of PCM women (268 of 663) and $41.5 \%$ of AMOP women (271 of 653) received telephone support. Of these women, 197 (73.5\%) in the PCM group received only 1 call, whereas $71(26.5 \%)$ received 2 or 3 calls; 246 (90.8\%) in the AMOP group received 1 call, and $25(9.2 \%)$ received 2 or 3 calls.

Table 2 shows changes in screening up-to-date status for the 3 cancers on an intent-to-treat basis, that is, regardless of whether a woman was successfully reached by telephone. In both unadjusted and adjusted comparisons, PCM women were more likely to be up-to-date for colorectal cancer screening after the intervention than AMOP women, with an odds ratio adjusted for baseline status of 1.69 (95\% CI, 1.03-2.77; $P=.04)$. Follow-up rates for breast and cervical cancer 
Figure 2. Flow of participants through randomization and treatment.

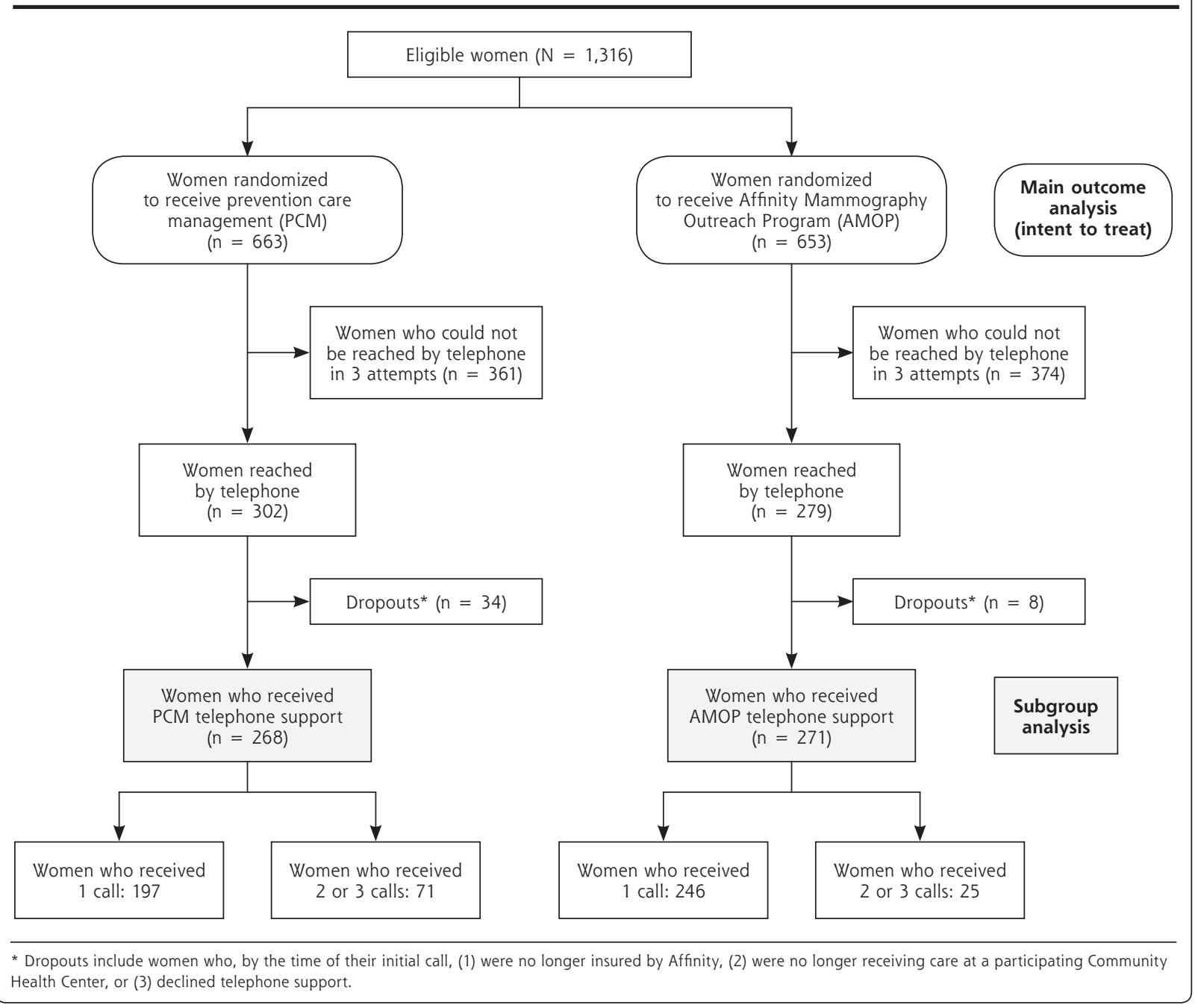

Table 2. Comparison of Up-to-Date Status Between Study Groups, at Baseline and at Follow-up, According to Intent-to-Treat Analysis Among All Women

\begin{tabular}{|c|c|c|c|c|c|c|}
\hline \multirow[b]{2}{*}{ Screening } & \multirow{2}{*}{$\begin{array}{l}\text { PCM } \\
\text { No. }(\%) \\
\text { Up-to-Date }\end{array}$} & \multirow{2}{*}{$\begin{array}{l}\text { AMOP } \\
\text { No. }(\%) \\
\text { Up-to-Date }\end{array}$} & \multicolumn{2}{|c|}{ Unadjusted Comparison } & \multicolumn{2}{|c|}{ Adjusted Comparison* } \\
\hline & & & OR $(95 \% \mathrm{Cl})$ & $P$ Value & OR $(95 \% \mathrm{CI})$ & $P$ Value \\
\hline Breast & $(n=663)$ & $(n=653)$ & & & & \\
\hline Baseline & $219(33)$ & $217(33)$ & $0.99(0.78-1.26)$ & .94 & $0.97(0.75-1.27)$ & .85 \\
\hline Follow-up & $343(52)$ & $326(50)$ & $1.08(0.86-1.34)$ & .51 & $1.16(0.86-1.57)$ & .33 \\
\hline Cervical & $(n=663)$ & $(n=653)$ & & & & \\
\hline Baseline & $344(52)$ & $333(51)$ & $1.04(0.83-1.29)$ & .75 & $1.03(0.83-1.29)$ & .76 \\
\hline Follow-up & $423(64)$ & $403(62)$ & $1.09(0.87-1.38)$ & .43 & $1.18(0.82-1.70)$ & .38 \\
\hline Colorectal ${ }^{\dagger}$ & $(n=317)$ & $(n=309)$ & & & & \\
\hline Baseline & $56(18)$ & $48(16)$ & $1.17(0.75-1.82)$ & .47 & - & - \\
\hline Follow-up & $103(32)$ & $78(25)$ & $1.43(0.99-2.05)$ & .05 & $1.69 \neq(1.03-2.77)$ & .04 \\
\hline \multicolumn{7}{|c|}{$\begin{array}{l}\text { * Baseline breast and cervical comparisons are adjusted for age ( } 40 \text { to } 49 \text { years, } 50 \text { years and older); there is no adjusted colorectal baseline comparison because this anal- } \\
\text { ysis included only women aged } 50 \text { years and older. Follow-up comparisons are adjusted for age (breast and cervical) and for baseline screening status (all } 3 \text { screenings). } \\
\dagger \text { Smaller } n \text { values for colorectal screening reflect the subset of the study population who were eligible for colorectal cancer screening (ie, aged } 50 \text { years and older). } \\
\neq P \leq .05 \text {. }\end{array}$} \\
\hline
\end{tabular}


screenings were not significantly different between the 2 groups in the intent-to-treat analysis. The findings were similar when women who were up-to-date on a given screening at baseline were excluded from analysis (Supplemental Table 1, available online-only

\section{$8 m_{1}$} at http://www.annfammed.org/cgi/content/ full/5/4/320/DC1). Of note, however, at follow-up in all women aged 50 years or older, women assigned to PCM were almost twice as likely to be up-to-date for all 3 tests $(59$ of $317,18.6 \%$ ) as their counterparts assigned to AMOP (33 of 309, 10.7\%), with an odds ratio adjusted for baseline status of 2.00 (95\% CI, 1.24 3.22; $P<.01$ ) (not shown).

Because many women in both groups could not be reached for the first call within the 3 -attempt call limit and thus did not receive the telephone portion of either intervention, we conducted a subgroup analysis of those women who were reached at least once. As displayed in Table 3, up-to-date rates for all 3 cancer screenings increased more in the PCM group than in the comparison group, and the difference was statistically significant for cervical cancer screening adjusted for age and baseline status, with an odds ratio of 1.86 (95\% CI, 1.08-3.21). The findings were again similar when women who were up-to-date on a given screening at baseline were excluded from analysis (Supplemen-

tal Table 2, available online-only at http://www. annfammed.org/cgi/content/full/5/4/320/DC1).

\section{DISCUSSION}

This trial aimed to explore whether PCM could be adapted to fit and have an impact when offered through a managed care organization's telephone support infrastructure. Our results show that modified PCM could be implemented and did modestly improve cancerscreening rates. The odds ratio of 1.69 for colorectal cancer screening is comparable to results of other mail and telephone outreach interventions to increase cancer screening, most commonly reported for mammography. Luckmann et $\mathrm{al}^{29}$ has reported odds ratios of 1.2 and 1.3 in 2 health maintenance organizations (HMOs) using tailored telephone counseling to increase mammography screening, and Lipkus et $\mathrm{al}^{30}$ found that female $\mathrm{HMO}$ patients who received telephone counseling were 1.69 times more likely to be up-to-date for mammography than women receiving usual care. Valanis and colleagues $^{31}$ achieved better results with an outreach intervention directed at both mammography (odds ratio $=2.94)$ and Pap testing (odds ratio $=2.92)^{\text {i however, }}$ their study population was demographically very different from that reported in our study.

We had a number of reasons to expect that the impact of PCM would be modest at best. Women in the comparison group received Affinity's usual care, that is, the existing mammography outreach program, with 2 enhancements (mailed information and brief encouragement to discuss other cancer-screening tests with their physician). The study therefore had no true control group. Such a no-contact control group is unlikely to be acceptable to HMOs that may already provide mail or telephone cancer-screening outreach as part of their mission and to improve HEDIS performance. ${ }^{26,32}$ The enhancements to the AMOP usual-care program were added at the direction of Affinity leaders who insisted on providing all women with this poten-

Table 3. Comparison of Up-to-Date Status Between Study Groups, at Baseline and at Follow-up, According to Subgroup Analysis Among Women Reached by Telephone at Least Once, Still Eligible, and Willing to Participate

\begin{tabular}{|c|c|c|c|c|c|c|}
\hline \multirow[b]{2}{*}{ Screening } & \multirow{2}{*}{$\begin{array}{c}\text { PCM } \\
\text { No. (\%) } \\
\text { Up-to-Date }\end{array}$} & \multirow{2}{*}{$\begin{array}{c}\text { AMOP } \\
\text { No. (\%) } \\
\text { Up-to-Date }\end{array}$} & \multicolumn{2}{|c|}{ Unadjusted Comparison } & \multicolumn{2}{|c|}{ Adjusted Comparison* } \\
\hline & & & OR $(95 \% \mathrm{Cl})$ & $P$ Value & OR $(95 \% \mathrm{Cl})$ & $P$ Value \\
\hline Breast & $(n=268)$ & $(n=271)$ & & & & \\
\hline Baseline & $111(41.4)$ & $133(49.1)$ & $0.73(0.51-1.05)$ & .07 & $0.69(0.46-1.04)$ & .08 \\
\hline Follow-up & $192(71.6)$ & $193(71.2)$ & $1.02(0.69-1.51)$ & .91 & $1.39(0.88-2.20)$ & .16 \\
\hline Cervical & $(n=268)$ & $(n=271)$ & & & & \\
\hline Baseline & $155(57.8)$ & $160(59.0)$ & $0.95(0.67-1.36)$ & .78 & $0.95(0.68-1.35)$ & .79 \\
\hline Follow-up & $207(77.2)$ & $195(72.0)$ & $1.32(0.88-1.99)$ & .16 & $1.86^{\dagger}(1.08-3.21)$ & .03 \\
\hline Colorectal ${ }^{\ddagger}$ & $(n=152)$ & $(n=160)$ & & & & \\
\hline Baseline & $25(16.4)$ & 27 (16.9) & $0.97(0.51-1.84)$ & .92 & - & - \\
\hline Follow-up & $52(34.2)$ & $44(27.5)$ & $1.37(0.82-2.29)$ & .20 & $1.84(0.95-3.58)$ & .07 \\
\hline
\end{tabular}


tially beneficial information, thus attenuating differences between study groups still further.

This administrative request to alter the research design to better fit a patient-centered orientation is part of the landscape when conducting research within an $\mathrm{HMO}$ and a quality improvement effort. Such compromises in ability to evaluate interventions rigorously developed with research support are an integral part of practical trials to enhance the buy-in of organizations and facilitate the design of sustainable real-world interventions. ${ }^{33}$

Not only was the comparison group here provided with more support than in the original study, ${ }_{1}^{12}$ but the PCM intervention itself was also modified in ways that might be expected to decrease its impact. First, telephone contacts were limited to no more than 3 over 8 months, whereas in the earlier study, the number of contacts was unlimited and could be provided over 18 months. Second, attempts to contact women, up to 8 in the earlier study, were limited here to 3. As a result, fewer than one-half of the women were successfully contacted even once. This lower contact rate was predicted by MMCO staff based on previous outreach experience and differed substantially from that in our original study, in which $91 \%$ of women assigned to PCM received at least 1 contact. Other studies that have made 10 or even 15 attempts to reach individuals before considering them unreachable ${ }^{29,34}$ have achieved much higher contact rates.

Differences in the impact of PCM across screening tests are worthy of note. It is no surprise that mammography rates at follow-up were similar between groups because both received the established $\mathrm{MMCO}$ mammography outreach program including a financial incentive. Baseline rates for colorectal cancer screening were the lowest of the 3 and thus had the most potential for improvement, as was shown in the intentto-treat analysis. The subgroup comparison for this test among women contacted at least once did not achieve statistical significance, although the sample size of those reached was small. Cervical cancer screening at follow-up adjusted for age and baseline status favored the PCM group in the subgroup analysis among women contacted at least once, but not in the intentto-treat analysis. For this service, baseline up-to-date rates exceeded $50 \%$ and increased about 10 percentage points for both groups in the intent-to-treat analysis.

Limitations of this study include its reliance on administrative data, which may be incomplete. ${ }^{35}$ Use of deidentified administrative data also limited the socioeconomic data available on study participants and the exploration of differences across the 6 health centers where the women received primary care. In addition, we did not have the resources to collect detailed cost-effec- tiveness data. The study, furthermore, was restricted to women in 1 metropolitan area served by $1 \mathrm{MMCO}$, limiting the generalizability of findings. Finally, there are scant published data on the proportion of HMOs and MMCOs that currently provide telephone outreach to members. ${ }^{32}$ Although our own informal surveys of industry associations have indicated that telephone outreach is increasingly common, the effort required to incorporate PCM into an HMO that lacked an established telephone outreach program would be substantial

Certain study strengths should also be noted. This effectiveness trial ${ }^{36}$ was conducted in a real-world setting with the intervention provided by established outreach staff who were not hired by or receiving fidelity monitoring from an external research team. Packaging the 3 screenings into a single intervention increased telephone outreach efficiency while providing a consistent approach for women across tests. Further, the target population-drawn from lower socioeconomic groups and having a high proportion of minoritieshas low rates of cancer screening and deserves a high priority for attention.

This study replicated the original finding that PCM can increase cancer screening and thus supports the idea that a telephone care management intervention on cancer screening can be translated to a real-world infrastructure. This study also suggests that administrative data can be used to help target women needing services and to monitor whether they receive needed services over time. The impact of the intervention was modest but statistically and clinically meaningful, despite a substantial "voltage drop" ${ }^{137}$ from the original PCM intervention. Future research should explore the impact of both similarly abbreviated and more robust PCM interventions in a range of sustainable settings. Additional studies should consider how to incorporate the PCM intervention with other health plan disease management and health promotion activities that seek to improve the quality of care.

To read or post commentaries in response to this article, see it online at http://www.annfammed.org/cgi/current/full/5/4/320.

Submitted October 25, 2006; submitted, revised, February 16, 2007; accepted March 18, 2007.

Key words: Breast neoplasms/ethnology/prevention $\&$ control; colorectal neoplasms/ethnology/prevention \& control; uterine cervical neoplasms/ethnology/prevention $\&$ control; telephone; managed care programs; poverty; New York City; intervention studies; Medicaid

Funding support: This project was supported by a National Cancer Institute dissemination supplement, R01 CA087776-04S1. Clinical Trials Registry number: NCT00376909 (ClinicalTrials.gov).

Acknowledgments: We gratefully acknowledge the assistance of Carolyn Cocotas, MPA, Maribel Mercado, and Melissa Torres of Affinity Health Plan; Richard G. Younge, MD, MPH, Clinical Directors 
Network and Montefiore Medical Group/Fordham Family Practice; Carrie Klabunde, PhD, of the Division of Cancer Control and Population Sciences, National Cancer Institute; and the participating Community Health Centers: Jacobi Health Center at Tremont, Martin Luther King, Jr, Health Center, Montefiore Comprehensive Family Care Center, Morris Heights Health Center, Soundview Community Health Center, Urban Health Plan.

\section{References}

1. Jacobellis J, Cutter G. Mammography screening and differences in stage of disease by race/ethnicity. Am J Public Health. 2002;92(7):1144-1150.

2. O'Malley AS, Forrest CB, Feng S, Mandelblatt J. Disparities despite coverage: gaps in colorectal cancer screening among Medicare beneficiaries. Arch Intern Med. 2005;165(18):2129-2135.

3. National Healthcare Disparities Report, 2003. U.S. Department of Health and Human Services, Agency for Healthcare Research and Quality; 2003. http://www.ahrq.gov/qual/nhdr03/nhdr03.htm. Accessed 20 October 2006.

4. Mayberry RM, Coates RJ, Hill HA, et al. Determinants of black/ white differences in colon cancer survival. J Natl Cancer Inst. 1995;87(22):1686-1693.

5. Smedley BD, Stith AY, Nelson AR, eds. Committee on Understanding and Eliminating Racial and Ethnic Disparities in Health Care, and Board on Health Sciences Policy, Institute of Medicine. Unequal Treatment: Confronting Racial and Ethnic Disparities in Health Care. Washington, DC: National Academies Press; 2003.

6. Chien C, Morimoto LM, Tom J, Li Cl. Differences in colorectal carcinoma stage and survival by race and ethnicity. Cancer. 2005;104(3):629-639.

7. Hiatt RA, Pasick RJ, Stewart S, et al. Community-based cancer screening for underserved women: design and baseline findings from the Breast and Cervical Cancer Intervention Study. Prev Med. 2001;33(3):190-203.

8. Centers for Disease Control and Prevention. Breast cancer screening and socioeconomic status-35 metropolitan areas, 2000 and 2002. MMWR Morb Mortal Wkly Rep. 2005;54(39):981-985.

9. Thorpe LE, Mostashari F, Feldman G, et al. Cancer screening in New York City: we can do much better. NYC Vital Signs. 2003;2(2):2003.

10. Mitchell MK, Gregersen PK, Johnson S, Parsons R, Vlahov D. The New York Cancer Project: rationale, organization, design, and baseline characteristics. J Urban Health. 2004;81(2):301-310.

11. Karpati A, Kerker B, Mostashari F, Singh T, Hajat A, Thorpe L. Health Disparities in New York City 2004. New York, NY: New York City Department of Health and Mental Hygiene; 2004.

12. Dietrich AJ, Tobin JN, Cassells A, et al. Telephone care management to improve cancer screening among low-income women: a randomized, controlled trial. Ann Intern Med. 2006;144(8):563-571.

13. Davis K. A need to transform the U.S. health care system: improving access, quality, and efficiency. Plenary address to the National Association of Community Health Centers Strategic Planning Retreat, Washington, DC, March 27, 2006.

14. Tunis SR, Stryer DB, Clancy CM. Practical clinical trials: increasing the value of clinical research for decision making in clinical and health policy. JAMA. 2003;290(12):1624-1632.

15. Glasgow RE, Magid DJ, Beck A, Ritzwoller D, Estabrooks PA. Practical clinical trials for translating research to practice: design and measurement recommendations. Med Care. 2005;43(6):551-557.

16. Kell SH, Allison JJ, Brown KC, Weissman NW, Farmer R, Kiefe C. Measurement of mammography rates for quality improvement. Qual Manag Health Care. 1999;7(2):11-19.
17. Diamond C, Rask K, Kohler S. Use of paper medical records versus administrative data for measuring and improving health care quality: are we still searching for a gold standard? Dis Manage. 2001:4(3):121-130.

18. Insinga RP, Glass AG, Rush BB. Pap screening in a U.S. health plan. Cancer Epidemiol Biomarkers Prev. 2004;13(3):355-360.

19. Roetzheim RG, Christman LK, Jacobsen PB, et al. A randomized controlled trial to increase cancer screening among attendees of community health centers. Ann Fam Med. 2004;2(4):294-300.

20. Roetzheim RG, Christman LK, Jacobsen PB, Schroeder J, Abdulla R, Hunter S. Long-term results from a randomized controlled trial to increase cancer screening among attendees of community health centers. Ann Fam Med. 2005;3(2):109-114.

21. Crabtree BF, Miller WL, Tallia AF, et al. Delivery of clinical preventive services in family medicine offices. Ann Fam Med. 2005;3(5):430-435.

22. Sardell A. Clinical networks and clinician retention: the case of CDN. J Community Health. 1996;21(6):437-451.

23. Humphrey LL, Helfand M, Chan BK, Woolf SH. Breast cancer screening: a summary of the evidence for the U.S. Preventive Services Task Force. Ann Intern Med. 2002;137(5 Part 1):347-360.

24. U.S. Preventive Services Task Force. Screening for Cervical Cancer: Recommendations and Rationale. Rockville, Md: Agency for Healthcare Research and Quality; 2003.

25. U.S. Preventive Services Task Force. Screening for colorectal cancer: recommendation and rationale. Ann Intern Med. 2002;137(2):129-131.

26. National Committee for Quality Assurance. HEDIS 2005 Summary Table of Measures and Product Lines. 2005. http://www.ncqa.org/ Programs/HEDIS/2005/MeasuresList.pdf. Accessed 20 October 2006.

27. Ogedegbe G, Cassells AN, Robinson CM, et al. Perceptions of barriers and facilitators of cancer early detection among low-income minority women in community health centers. J Natl Med Assoc. 2005;97(2):162-170.

28. Stata Statistical Software; release 8.0 program. College Station, Tex: Stata Corp; 2003.

29. Luckmann R, Savageau JA, Clemow L, Stoddard AM, Costanza ME. A randomized trial of telephone counseling to promote screening mammography in two HMOs. Cancer Detect Prev. 2003;27(6):442-450.

30. Lipkus IM, Rimer BK, Halabi S, Strigo TS. Can tailored interventions increase mammography use among HMO women? Am J Prev Med. 2000;18(1):1-10.

31. Valanis BG, Glasgow RE, Mullooly J, et al. Screening HMO women overdue for both mammograms and Pap tests. Prev Med. 2002;34(1):40-50.

32. Goins KV, Zapka JG, Geiger AM, et al. Implementation of systems strategies for breast and cervical cancer screening services in health maintenance organizations. Am J Manag Care. 2003;9(11):745-755.

33. Altman DG. Sustaining interventions in community systems: on the relationship between researchers and communities. Health Psychol. 1995;14(6):526-536.

34. Costanza ME, Stoddard AM, Luckmann R, White MJ, Spitz Avrunin J, Clemow L. Promoting mammography: results of a randomized trial of telephone counseling and a medical practice intervention. Am J Prev Med. 2000;19(1):39-46.

35. Walsh EG, Osber DS, Nason CA, Porell MA, Asciutto AJ. Quality improvement in a primary care case management program. Health Care Financ Rev. 2002;23(4):71-84.

36. Glasgow RE, Lichtenstein E, Marcus AC. Why don't we see more translation of health promotion research to practice? Rethinking the efficacy-to-effectiveness transition. Am J Public Health. 2003;93(8):1261-1267.

37. Eisenberg JM, Power EJ. Transforming insurance coverage into quality health care: voltage drops from potential to delivered quality. JAMA. 2000;284(16):2100-2102. 